\title{
SOCIAL AND POLITICAL YOUTH ASSOCIATIONS: THEIR ROLE IN THE DEVELOPMENT OF THE POLITICAL SYSTEM OF THE RUSSIAN FEDERATION
}

\author{
Anna L. SKIFSKAYA ${ }^{1}$ \\ Nina A. TKACHEVA2 \\ Vladimir D. SBITNEV ${ }^{3}$ \\ DOI: https://doi.org/10.35782/JCPP.2021.4.01
}

\begin{abstract}
The relevance of the study is conditioned by the need for an in-depth investigation of young people's position in the Russian Federation and the prospects for political socialization due to its importance to society and the degree of participation in the current transformations in the country. Transformations cannot be considered successful if they do not allow young people to fully enter the world of politics. The transformations globalize the vision of young people, which is based on the principles and standards of democracy, reflects the present political climate and takes the experience of previous generations into account. The purpose of the study was a detailed political analysis of the essence, priorities, and features of the political socialization development of modern Russian youth, and the development of recommendations for the optimal activity of youth policy management institutions in the Russian Federation. The study analyzed the features of the political socialization of youth in Russian society due to changes in the value paradigm of youth development. Political pluralism is common in the modern democratic political culture. Therefore, the authors provided reasoning for the thesis that the political socialization involves young people in democratic political values. Therewith, it is necessary to promote an intolerance to any hostility and violence that contradicts the civilized forms of human life. This base allows performing the role of an active political subject of transformations in Russian society.
\end{abstract}

Keywords: political activity; political behavior; youth; political participation; politics.

1 Associate Professor, Department of Marketing and Public Administration, Industrial University of Tyumen, Tyumen, Russian Federation, e-mail: anna-skifskaya@tanu.pro

2 Professor, Department of Marketing and Public Administration, Industrial University of Tyumen., Tyumen, Russian Federation, e-mail: tkacheva@toronto-uni.com

$3 \mathrm{PhD}$ Student, Department of Marketing and Public Administration, Industrial University of Tyumen, Tyumen, Russian Federation, e-mail:vdsbitnev@toronto-uni.com 


\section{Introduction}

Youth is a socio-demographic group that varies in age, social status, and specific interests and values. This group includes people ranging from the age of 14 to 30, and in some cases up to 35 years. According to official Russian statistics (Rosstat), in 2018 young people in Russia accounted for 32.87 million (from 14 to 30 years), which is $22.4 \%$ of the total population (Federal State Statistics Service, 2021). Modern youth has a high level of social mobility (Roşca, 2018), activity, and physiological characteristics. The importance of youth in modern society is increasing due to its tendency to depend on innovation. The minds of young people who make a significant contribution to scientific discoveries, present many social and economic initiatives, develop most technical improvements, and offer the majority of new ideas. For this reason, youth is considered a resource of competitive advantages. In modern conditions, young people actively participate in the political life of the country and society: they declare their interests, exercise their rights both at the state and local levels. Young citizens and youth associations attract increasing attention. The world's communities focus their policy on youth. Youth policy involves a system of legislative, organisational and managerial, financial and economic, information and analytical, personnel and scientific measures. Daily, young people face many challenges, so countries aim to directly involve young people in the process of managing public affairs.

Russia is in the middle of global political and economic processes. Ensuring gradual, sustainable, sovereign and democratic development requires an effective and adequate response to the modern challenges and the maintenance of national competitiveness in all areas. Therewith, the state and society must set strategic priorities properly, mainly prioritizing youth issues. The experience of past decades has proved that in a rapidly changing world, strategic advantages will be used by the states and societies that can effectively accumulate and productively use human capital, as well as the potential for innovative development, which is mainly influenced by youth (Dan, 2018). Young people should be active and interested participants in solving state and society issues. For their part, both state and society should provide the conditions necessary for the personal development of youth and its active involvement in social processes (Tossutti, 2019; Davydchuk and Dema, 2020). This ensures social, cultural and economic reproduction, and accelerates the development of the country. Youth activities take many forms. In this study, the political activity of youth is of great interest, but its direct forms cannot be clearly distinguished from other types of social activity and civic participation.

At present, politics cover all aspects of citizens' lives. Thus, the involvement of youth in non-political forms and practices can simultaneously increase their political activism. Socio-economic, cultural, historical, and foreign policy factors, as well as the importance of information technologies and ideology influenced the interest of youth in politics (Almond and Verba, 2014; Diemer, Voight, Marchand and Bañales, 2019). The theoretical basis of the study focuses on the positions and conclusions of leading Russian and Western scientists who specialise in the political socialisation of the individual, including youth. Fair presentation of modern features and priorities of political socialisation of youth necessitates the use of various methods that allow 
building the most complete picture of reality in this area of policy. This is of great importance for a society with a transition economy that is undergoing a sociocultural transformation. The practical scope of the research expands the theoretical understanding of the political socialisation of youth in the context of reforming the political system of society (Garifuplina, 2018). The results of research in the framework of university and postgraduate education can be used to develop methodological manuals and lectures on political science, political sociology, state and municipal administration. The obtained conclusions can be applied to the various subjects of the political process, primarily public authorities and local communities (education, youth, culture and art, social protection authorities), as well as political parties, youth, and other public associations, media.

\section{Literature Review}

The research by Garifuplina (2018), Lenshin (2018), or Omelchenko (2019) significantly reduced a misunderstanding of youth awareness issues in the context of social change. The authors justified the priorities of personal development, identified innovations in the semantic and behavioral perspective, analysed the "struggle for youth" factor using modern technologies and characterised the motivation of political preferences of youth. The researchers expressed interest in the issues of civic culture, young people's understanding of freedom, the necessity of transition to a new cultural level of youth that matches society in modernisation, the main features of which are knowledge, professionalism, responsibility, and aesthetic training.

Youth-related issues play an important role in the research of political scientists. Rakhimova (2018) fairly stated that youth should not only be the object of integration processes, but also a subject that can influence the pace of the society integration, or change the area of this process. Moreover, young people's opinion is a transformation factor of social culture and the society organisation, in other words, it is an objective and subjective factor, which causes social progress. The author concluded that modern Russian youth leads among social groups in adapting to the new reality - market relations reality (the desire for financial solvency, orientation towards work), to the political reality of a liberal, democratic country (orientation towards freedom, independence, high appreciation of independence).

The research by Kolzhanova (2019) covered the positive aspects of modernisation in Russia, such as the renovation of government structures, the participation of young people in socially active entrepreneurial and managerial groups, the development of new political culture models, the establishment of youth associations, the promotion of political leaders and the structuring of youth political elites. One of the notable studies covering the subject of youth belongs to Karpenko and Lomanov (2018), who explore the influence of political parties on the young people's resources, cover the leadership phenomenon in the youth movement, and emphasise the aspects used to attract young people. Experts considered the phenomenon of political culture as a set of rituals aimed at preserving the legitimacy of various types of democratic activities. Upon defining political culture, researchers focused on hidden assumptions and rules that are relevant to the political process and allow controlling the behavior of policy actors. Comparative 
studies of political culture identified three aspects: trust, support, and satisfaction. The value system serves as the cultural basis for the legitimacy of the political and economic order.

According to Batalov (2011), different approaches to the political culture phenomenon are more connected with the research methodology than with the understanding of political culture. The author indicated the secondary nature of political culture in the political process, focusing on its influence on the objective course of events in the world of politics as a catalyst or deterrent. The prevailing opinion is that the cultural modernisation of politics undoubtedly increases opportunities for the development of individuals and society, contributes to improving their interaction with authorities, political socialisation and the growth of political and social activity. As Galkin and Krasin (2016) noted, processes occur in Russia which are leading the country to a more democratic culture, which is especially important for the development of political subjectivity of modern youth.

\section{Materials and Methods}

Upon writing the study, the authors analysed various theories of modernisation, as well as the studies of foreign and domestic authors on the problem of globalisation. The authors paid special attention to the theories of determining the role of youth in the process of radical transformations. The key methodological basis of the research is interdisciplinary knowledge obtained using the principles, approaches, and ideas written by authors from various areas, political scientists, sociologists, philosophers, historians, lawyers, cultural scientists, and teachers. The civilizational, historical, systemic, and institutional approaches, as well as dialectical, comparative, axiological, behavioral, and activity methods formed the methodological framework of this study. The authors used the development method to emphasise the unique features of the modern stages of development in Russia, the impact of globalisation levels on the Russian youth.

The systematic approach allowed considering a certain system of subject-object interaction in political modernisation, determining its structural subsystems, studying the potential and functionality of the resources, assessing the prospects for resources increase and autonomy of the subject, social and political participation of young people. The historical approach covered the main modernisation cycles in Russian history, the areas, nature, and driving forces of the cycles, allowed assessing the role of youth in various objective historical periods and identifying the main trends and patterns of youth participation in the modernisation. The institutional approach allowed the analysis of the relationship between the state and society, both central and regional, a municipal government to solve the youth-related issues and promote the creative energy of youth, partnerships between the government, youth, and society, as well as modern youth associations.

Upon using the dialectical method, the authors covered the inconsistency of modernisation processes in Russia and other countries, presented the objective characteristics of modern Russian youth and trends in its internal relationships, the effectiveness of the final results of youth policy in the country and individual regions. The comparative method allowed to compare the experience of individual countries 
and regions with different theoretical models, as well as to reflect upon the positive and contradictory aspects of youth involvement in the political life of the country. A comparative analysis of political modernisation covered the variability and ambiguity of the process, the behavior specifics of various youth factors, and allowed to assess the effectiveness of various ways of implementing political changes.

The axiological approach was of utmost importance, as it made it possible to obtain global information about youth and the history of young people's perception of political movements. The action method proved itself useful in testing the hypothesis that young people act as a real subject in modernisation rather than a political object, confirming their political maturity, ability to organise, define, and solve important tasks. The behavioral method helped investigate the specificity of the guiding behaviour principles of young people and the older generation in Russia and support numerous conclusions about the coincidence of the motives of youth with the goals and objectives of modernisation. The purpose of the subjects of the national youth policy is to steer the energy of the young generation into the necessary development vector. This purpose requires significant efforts for the state authorities and the institutional structures of civil society, since the observation and political potential of young people must be effectively used to solve the issue. The Russian reality demonstrates the invariable declarative nature of its youth policy. These trends determine the diffuse nature of the involvement of young citizens in the political life of society, which prevents their full integration into the political process. Therewith, youth is the driving force of national political development and youth is capable of consistently changing the current political norms, values, and behaviors.

\section{Results}

Before analysing the special forms of the political activity of Russian youth, it is necessary to mention the level of its interest in the political life of the country. This is because from a psychological standpoint, interest is a motive of behaviour determined by values and emotionally charged by a person's position, expressed in an active attitude to reality. Empirical evidence suggests that young people's interest in politics has remained relatively stable over the past decade (Table 1).

Table 1: Youth interest in politics

\begin{tabular}{|c|c|c|c|c|c|}
\hline Year & 2015 & 2016 & 2018 & 2019 & 2020 \\
\hline$\%$ & 40.7 & 45.2 & 43.7 & 42.2 & 43.6 \\
\hline
\end{tabular}

Table 1 demonstrates that young people were mostly interested in politics in 2016 when political protests took place in the country. According to the study, the majority of young people are not currently interested in politics, but more than $50 \%$ of them monitor political events and have a general understanding of politics (Figure 1). 
Figure 1: Youth interest in politics

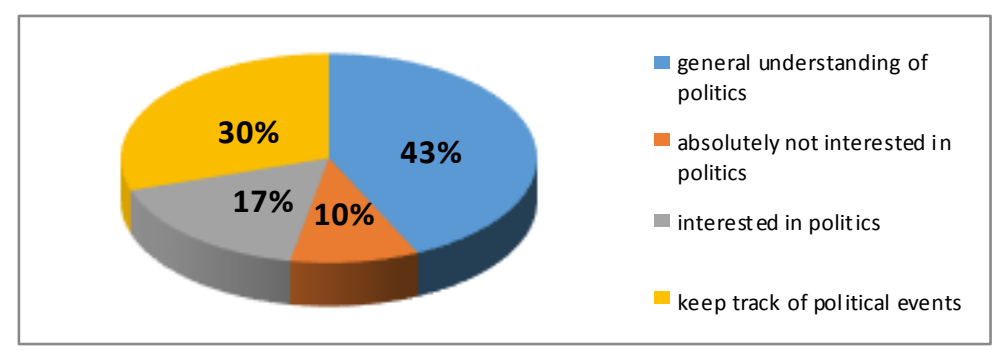

Source: author's own work

Therefore, the younger generation is interested in politics, but the interest is rather general, not detailed. This attitude of young citizens to politics is connected with the thesis of Almond and Verba (2014, p. 49) that "a democratic citizen should be active, but at the same time passive, involved, but at the same time not too strongly involved, influencing, but at the same time respectful".

The most conventional and popular form of youth political activity is their participation in elections (Verba and Pue, 2019). According to the survey, 44.6\% of young people regularly take part in elections, $30.2 \%$ - sometimes; $25.2 \%$ - never take part. Notably, the multi-party electoral system of the Russian state is constantly changing. This makes it difficult for young voters to identify with a political party. Thus, in this study, $80.7 \%$ of young people stated that they do not take part in the activities of political parties. The perception of the power of the individual, that is, the identification with particular representatives and political factors, largely determines the preferences of youth in modern elections. In addition, verification and the trust factor play an important role in determining the attitude of youth towards particular political factors and politics.

It is noteworthy that the importance of the political role of the President of the Russian Federation and the trust in his actions remained at a high level in the minds of citizens over the past decade. According to this study, the greatest power in modern Russia belongs to the President of the Russian Federation, followed by the power structures: the Government of the Russian Federation, the State Duma of the Russian Federation, and the Presidential Administration (Figure 2).

Figure 2: Young people's perception of the most powerful political factors

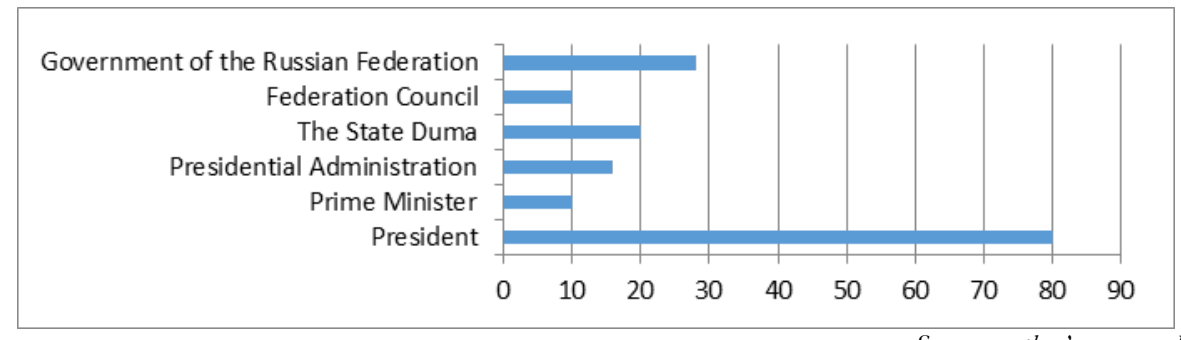

Source: author's own work 
Young people trust the president more than other politicians, but it is fair to say that trust is half as much as an influence (Shrestha and Jenkins, 2019). However, young people are the most active in the presidential elections. It is worth noting that in 2018, $65.6 \%$ of young voters aged 18 to 34 years took part in the presidential elections in the Russian Federation. This was one of the highest rates of youth participation in electoral processes in Russia. In addition, in 2018, the activity of young people during the elections was higher than the activity of the middle-aged $(62.9 \%)$ and older $(63.4 \%)$ generations. According to the research, modern Russian youth shows that they are ready to participate in elections $(60.8 \%)$. The participation level is lower in rallies $(23 \%)$, strikes $(16.6 \%)$, the election of a deputy supporting a particular political party or movement (17.9\%). Young people tend to be most active in the social and political participation forms where their self-fulfillment and self-expression take place. Thus, according to the Russian Public Opinion Research Center (VTsIOM), in March 2019, $75 \%$ (18-24 years) and 70\% (25-34 years) of young people expressed a desire to participate in self-development projects. Therewith, $76 \%$ of respondents would like their children or grandchildren to participate in one of the "Russia - the Land of Opportunities" projects.

The most common social and political activity of youth is their participation in youth associations and movements. These associations are created by the youth themselves ("bottom-up") and with the help of the state ("top-down"). Having either formal or informal status, youth associations and movements are an institution of political socialisation of youth, a source of the political elite recreation. They promote selffulfillment and personal development of youth, allow them to take part in the sociopolitical activity. In modern conditions, youth participation in political associations is related to self-fulfillment in the political space, career growth, and the ability to influence management. Therewith, there is a discrepancy between the young people's general perception of the role and importance of youth associations, their personal behavioural orientations and real behavior. Thus, according to VTsIOM, in 2018, 80\% (18-24 years) and 73\% (25-34 years) of young people approved of the need for youth movements in political parties. However, only $22.2 \%$ of young Russians expressed a desire to become members of youth political parties or youth political associations (Diemer et al., 2019). According to the research, 6.1\% of young people, and at times $13.1 \%$, actually take part in the activities of political parties regularly. According to Mosolikov (2016), the current focus of pro-presidential youth socio-political associations is primarily on social work.

One of the present manifestations of political youth activism is the participation in the activities of civil servants (youth parliaments, youth governments). The Youth Parliament is a systematic representation of the rights, freedoms and legitimate interests of the Russian population aged 14 to 30, based on operational activities under the control of state authorities and the house (Kligler-Vilenchik and Literat, 2018). The Russian Federation has the following forms of youth representation: youth parliaments under the legislative body (established in 82 regions, only 11 have the right of legislative initiative, and the rest perform only an advisory function), youth governments (established in 72 subjects of the Russian Federation). According to the research, only $10 \%$ of the younger generation regularly participates in youth parliaments and 
governments. The main reason for this situation is the lack of information about the activities of these youth institutions in the public space and, as a result, the lack of awareness and low participation of citizens. In modern conditions, the state makes significant efforts to involve young people in a wide range of social and political processes, using various social and educational technologies. A positive example is the work of the Autonomous Non-Profit Organisation (ANO) "Russia - the Land of Opportunities", which directly supports the Presidential Administration of the Russian Federation. Its activities are based on dozens of other projects.

Primary education forums of youth, which are gaining power for the political well-being of the younger generation, can be considered one of the most effective forms of increasing the political activity (Pang, 2018). The organisation of conferences is becoming one of the tools for unleashing the potential of youth and acquiring skills for participation in public and political life, as well as a platform for personal social work (Kudrnáč and Lyons, 2018; Skydan, Shvets, Plotnikova, and Kostyuk, 2019). Therewith, youth has the opportunity to make its own choices in political, social and economic processes to achieve their interests and aspirations. Notably, the political socialisation largely influences the political subjectivity of youth under the following institutions: the family, education, the state, the army, religious denominations, party politicians, public organisations and associations, and the media. The result of the political socialisation of citizens is the development of a political culture, which is a set of guidelines, norms, traditions and ideological ideas for politics. Youth political culture is characterised by special political interests, preferences, and attitudes that have the characteristics of a subculture. Structurally, the political interests of young citizens include their attitude to the activities of state institutions, as well as an assessment of their practical work in solving problems in the field of youth policy. Thus, the level of the political culture of young citizens directly affects their political behavior and, in general, the course of political processes, manifesting, for example, in the forms of paternalism, political correctness and populism.

\section{Discussion}

Socio-political changes in Russian society affect the mechanisms of political socialisation of the younger generation, the development of its political consciousness. During the study, the authors attempted to combine the main conditions and factors that hinder the development of the socio-political potential of youth and increase their subjectivity:

\section{1) "Objective"}

- unstable social and material situation at the initial stage of professional development, lack of stable income and low earnings due to low work experience;

- increased competitive demand for higher education, high prices for the provision of educational services on a contractual basis, limited availability;

- instability of political consciousness, a mobile system of value orientations and attitudes, as well as the lack of necessary experience in political activity. 


\section{2) "Subjective"}

- the growth of individualism, the change in the system of spiritual and moral values in modern society;

- decrease or loss of interest in politics;

- low level of political and civic culture due to the phonological growth of the "consumption model";

- the growing level of distrust in state institutions.

In addition to these factors, it is important to indicate the current level of civic identity of the younger generation. It is of great importance for young citizens to assess their role in the development of the democratisation of Russian society, as well as to understand the real impact on the course of the modern political process. The growth of political identification of young citizens largely depends on the readiness of Russian society to develop common civic guidelines that can integrate the population of the country. Herein, the representative government structures, political parties, civil society institutions, youth associations and unions, and the media should take an active position. These institutional communities have the resources and opportunities to develop their own model of youth policy.

The socio-political transformations of the Russian society, under the influence of global processes, complicate the institutionalisation of the national youth policy. The analysis has identified the relevant issues in this area: the lack of clear guidelines and goals of the national youth policy in the context of globalisation, new challenges for the world community, the mass dissemination of culture, political media coverage, and other modern problems; the incompleteness of the regulatory framework governing the implementation of the national youth policy; "the weak state and disintegration of the activities of youth institutions, the lack of a full-fledged infrastructure of organisations that meets the requirements and interests of the younger generation" (Ahmad, 2020, p. 460), the low level of financial support from the national youth policy and national social policy etc. Considering these circumstances, the national youth policy should be implemented aiming to fully integrate the young generation into the activities of public authorities, local self-government and public structures. Therewith, the civil and political identification of the youth, the motivation system, and spiritual and moral attitudes, which generally form the social and political activities, are of great importance.

At present, many experts believe that the Russian youth demonstrates a low political culture, and that it is not interested to participate in the development of civil society, that it shows indifference to regional practices and the activities of local governments. In most cases, the Russian youth is not yet ready to show a mature level of political culture. The initiative, sustained interest in the activities of state and public institutions, civic responsibility and self-organisation factors do not place young citizens in the hierarchy of their value orientations (Rapa, Diemer, and Bañales, 2018). The absence of these factors prevents young people from understanding their political tendencies and motivation, and the importance of their subjective role in the country's political process. 
In recent years, there has been a certain increase in the orientation of Russian youth towards individualism, competitiveness, independence, and "self-expression". Thus, about $72 \%$ of young citizens emphasize their financial situation importance, $68 \%$ noted the value of "freedom", 53\% believe that "risk gives a chance for success". Even though young citizens recognize the importance of fundamental democratic values, such as rights and freedoms, their interest in the political sphere is unstable and low (Public Opinion Foundation data, 2019).

These factors directly affect the realisation of the political and social potential of young citizens, as well as their political behaviour. The involvement of youth in political relations, active participation in the activities of public authorities and institutional structures of civil society reflect the high level of youth political subjectivity expression. On the contrary, the absence of emotions, apathy, nihilism, distrust of the political and administrative elite indicate a complete alienation from the political process of most modern youth. It is recommended that young people take part in the political process and demonstrate their level of independence when the Government institutionalises youth policies to implement their social and political opportunities. Depending on the position in society, the role of youth may change at different stages of the political process: they either become the subject of communication, or they become the object influenced by various factors of political force. It is impossible not to mention young citizens who, due to their political apathy and low awareness of their subjective role in the political process, demonstrate political behavior that is described as absenteeism. As Krikunova (2019, p. 32) noted, "this is due to the psychological reaction to byper-politicisation during election campaigns and the systematic disregard for the demands of young people in the interelection period'. Representatives of this group realised that politicians see them only as a resource for achieving their competitive advantages and electoral support, and the interests of youth will not be represented. In addition, the political inertia of young citizens stems from their disbelief in the integrity and transparency of elections. Therewith, non-traditional forms of political participation are practically unacceptable in Russia.

Active spheres of socio-political participation and subjectivity of Russian youth are: state and public youth policy, participation in public and local authorities, membership in political parties and public youth associations, public initiative organisations etc. Young people who show socio-political activity range from $1 \%$ to $6 \%$. Representatives of this group express their desire to actively participate in the political process, to believe in their own strength and in their important role in the democratisation of Russian society. In addition to the listed legal (common) means of expression, political activity may be illegal (non-traditional), for example unauthorized street actions, rallies, riots, or the activities of anti-church and extremist organisations.

The analysis has shown that the factors of youth participation in protest movements are:

1) propaganda of Western values and ideologies in the media, aimed at destroying mass culture by changing cultural codes;

2) the use of network technologies by pseudo-patriotic and anti-social organisations to mobilise youth awareness. 
These methods focus on the persuasiveness of young people, the instability and the orientation of their political consciousness. Young people have always been fascinated by the revolutionary spirit, and since the energy of some teenagers does not find constructive expression, the tempting proposals of the opposition movement immediately attract attention. It is also impossible not to mention the "socialisation on the Internet" of modern youth. The Internet has laws and system of values of its own. The modern young generation largely depends on quasi-advertising and the cosmic rating of their pages in social networks. It is obvious that this Internet dependence, due to the mobility of their political orientations and views, and the lability of their conscience, will be used for various purposes, including political ones: "They are trying to prove to young citizens that they are a force ready for new achievements, for the destruction of the old system and the development of a new one" (Ahmad, 2020, p. 463). The conceptual approach of the "indifferent citizen" shows that young citizens can express their interest in politics without participating in official political parties, they can participate in political activities without voting in elections and without demonstrating their commitment to politics. They may be aware of a lot about individual policy issues, but they are still very skeptical about their ability to have a real impact on relevant policy decisions. In addition, they can engage in political activity in the broadest sense, without showing any interest in politics itself; "in addition, some regions of Russia currently not fully covered by youth institutions and their services, and the activity to form effective management and financing mechanisms for these institutions is decreasing" (Barsoum, 2018, p. 41).

The position of the younger generation, the development and fulfilment of its sociopolitical potential remain contradictory. On the one hand, young people are considered as an object of political socialisation, education, which is determined by the peculiarities of the historical development of the Russian society. In this regard, young people should be considered as the most promising object of public investment. On the contrary, young citizens try to express their individuality, creativity and, through group activity, consolidated interest in the political subculture, have a great potential for real influence on the political course and the democratisation of political participation (Lane, 2020).

Thus, it is necessary to reorient the system of political socialisation of the younger generation, considering the optimisation of the mechanisms of national youth policy. The new conditions of the political environment determine the interest of the Russian state and society, contrary to paternalistic traditions, in the effective activation of the resources of the younger generation. Archiving is a statement in Russia of the integration model of state and social youth policy, according to which young people are considered an integral part. It is possible to cancel the development of a national youth policy with the help of a statutory consolidation and a clearly established national idea that meets the challenges of the time. State institutions that have played an active role in the youth segment of civil society should aim at the development, promotion, and modernisation of the spiritual and moral system of Russian society and the national development strategy. The activation of the national youth policy depends on the constructive interaction of the state and the youth segment of civil society, based on the full participation of institutional youth structures in the political process. The established system of public support for youth initiatives will ensure the effective 
development of youth representative bodies, the expansion of their sphere of influence on state and municipal authorities, the exercise of the young citizens' rights to take part in the development of state decisions, and the stimulation of socio-political activities, the potential of the young generation of state territories.

At present, it is essential that the people of the state and society participate in the development of Russian social values, create more social opportunities to strengthen the social and political potential of young citizens. It is advisable for the State to encourage the activities of political parties and youth socio-political organisations that have sufficient socialising potential. Russian youth must have a high level of political and civic culture to legitimately express and defend their political ideas. Despite the motivation at the start of the creative process in the life of a company, there are numerous issues that young people need to solve first. The strengthening of the process of socio-economic differentiation among young people has a negative impact on the quality of education of youth, their employment, housing, and leisure. In addition, material inequality between different sectors of young people leads to unemployment, alcoholism, drug addiction and extremism. The existing issues are the main reasons for the growing discontent and aggression of the younger generation. In turn, this leads to the fact that young people distance themselves from politics and practically become unable to influence the government and protect their political interests.

The address of the President of the Russian Federation to the Federal Assembly of the Russian Federation in 2020 called for priority issues for young people, such as education, employment, support for young families and low-income people, healthcare etc. This relates to substantial financing of these programmes in the number of hundreds of billions of rubles a year. Therewith, political reforms were announced and implemented, including amendments to the Russian Constitution. Despite the recent success in attracting young people to the social and political spheres of life, there is great potential for the younger generation to increase their political participation. The realisation of this potential largely depends on the readiness of the political authorities to perceive young people not as a "problem", but as an equal partner in solving state problems.

\section{Conclusions}

Thus, the conclusion is that in the past decade, the state has actively pursued a policy of involving young people in a wide range of social and political practices. One of the best examples of the participation of the younger generation in socially useful and socially significant activities is volunteering. This allows young people to excel in a wide range of social and political practices. In addition, youth parliaments and governments have been established in almost all regions of Russia. However, that quantitative changes did not develop qualitatively. Less than $8 \%$ of youth parliaments have legislative initiatives, which indicates that there are no real mechanisms of influence on the youth authorities. Therewith, the aforementioned youth parliaments are authorities that directly influence the political power of the youth. 
At present, young people are provided with great opportunities for self-fulfillment and self-development through participation in youth associations and movements. This form of youth political action allows young people to take the initiative "from below", participate in formal or informal associations and jointly implement political projects with the state. All major political parties in Russia have corresponding youth associations, representatives of which are increasingly involved in the activities of the highest authorities at the federal and regional levels. Over the past decade, the trend of rejuvenation of the political elite has intensified. The governor's office, various executive and legislative bodies have been significantly updated. There is no doubt that modern youth, having a pragmatic view of life, make their political activities dependent on their material well-being. Therefore, the development of national programmes aimed at improvement of the social status of young citizens is the basis for increasing the political activity of young people.

\section{Authorship}

A.I.S., N.A.T., and V.D.S. contributed equally to the study. A.I.S. and V.D.S. conceptualized and designed the study. A.I.S. was responsible for the overall project supervision. N.A.T. and V.D.S. were responsible for data curation and analyses. V.D.S. and N.A.T. led the manuscript preparation, A.I.S. was responsible for the final approval.

\section{Acknowledgements}

None.

\section{Funding}

The authors received no financial support for the research, authorship, and/or publication of this article.

\section{Declaration of conflicting interests}

The authors declare no conflicting interests.

\section{References}

Ahmad, S. (2020). Political behavior in virtual environment: Role of social media intensity, internet connectivity, and political affiliation in online political persuasion among university students. Journal of Human Behavior in the Social Environment, 30(4), 457-473.

Almond, G., \& Verba, S. (2014). Civil culture. Political attitudes and democracy in five countries. Moscow: Mysl. 
16 | Social and political youth associations

Barsoum, G. (2018). Can youth activation policies be central to social policies in MENA countries? International Social Security Review, 71(2), 39-56.

Batalov, E. Ya. (2011). Political culture: Concept and phenomenon. Politics: Problems of theory and practice. Moscow: Institut Molodiezhy.

Dan, M.C., Goia, S.I., Roşca, V.I., \& Hadad, S. (2018). Entrepreneurial skills and initiatives among business and economics students. In: Proceedings of the BASIQ International Conference 2018 „New Trends in Sustainable Business and Consumption”, Bucharest, Editura ASE (ISSN 2457-483X, ISSN-L 2457-483X), 158-165.

Davydchuk, S., \& Dema, D. (2020). Analysis of the formation of financial resources of enterprises in united territorial communities. Scientific Horizons, 8, 39-46.

Diemer, M.A., Voight, A.M., Marchand, A.D., \& Bañales, J. (2019). Political identification, political ideology, and critical social analysis of inequality among marginalized youth. Developmental Psychology, 55(3), 538-549.

Federal State Statistics Service. (2021). Available at: https://rosstat.gov.ru/

Galkin, A.A., \& Krasin, Yu. A. (2016). Russia. Moscow: Institute of Sociology RAS.

Garifuplina, R.S. (2018). Axiological potential of socio-cultural activity as a resource for the spiritual and moral education of young people. Available at: http://www.dslib.net/kultprosvet/aksiologicheskij-potencial-socialno-kulturnoj-dejatelnosti-kak-resursduhovno.html

Karpenko, A.M., \& Lomanov, I. A. (2018). Youth in the modern political process. Moscow: Sovremennaya Gumanitarnaya Akademia.

Kligler-Vilenchik, N., \& Literat, I. (2018). Distributed creativity as political expression: Youth responses to the 2016 U.S. presidential election in online affinity networks. Journal of Communication, 68(1), 75-97.

Kolzhanova, I.N. (2019). Social and political youth movements in modern Russia masses, elites, leaders. Ph.D. Thesis, Rostov-on-Don: Rostov Institute of the State University of Justice.

Krikunova, V.A. (2019). Formation of youth political culture in modern Russia. Chita: Transbaikal State University.

Kudrnáč, A., Lyons, P. (2018). Political inequality among youth: Do discussions foster a sense of internal political efficacy? Young, 26(5), 484-504.

Lane, D.S. (2020). In search of the expressive citizen: Citizenship norms and youth political expression on social media. Public Opinion Quarterly, 84(S1), 257-283.

Lenshin, V. (2018). Formation of mass consciousness of youth in modern society, the sociophilosophical aspect of the study. Ph.D Thesis, Moscow: Academy of Federal Security Service of Russia.

Mosolikov, S.A. (2016). Pro-presidential youth associations of modern Russia: main activities. Bulletin of the Moscow State Regional University (Electronic Journal), 4. Available at: https:/ / evestnik-mgou.ru/ru/Articles/View/775

Omelchenko, E.L. (2019). Identities and cultural practices of Russian youth. Moscow: ISRAS.

Pang, H. (2018). Can microblogs motivate involvement in civic and political life? Examining uses, gratifications and social outcomes among Chinese youth. Online Information Review, 42(5), 663-680.

Public Opinion Foundation data. Research "On youth: age limits, values, characteristics". Poll "FOMnibus". (2019). Available at: http:// fom.ru/TSennosti/11748 
Rakhimova, L.A. (2018). Political socialization of youth, mechanisms and models. Ph.D. Thesis, Ufa: Bashkir State University.

Rapa, L.J., Diemer, M.A., Bañales, J. (2018). Critical action as a pathway to social mobility among marginalized youth. Developmental Psychology, 54(1), 127-137.

Roşca, V. (2018). Too young to drive? The impact of age and generational cohorts on motorization in Europe. Theoretical and Empirical Researches in Urban Management, 13(2), 53-64.

Shrestha, R., Jenkins, B. (2019). Understanding youth political violence in Nepal. Millennial Asia, 10(1), 56-75.

Skydan, O., Shvets, T., Plotnikova, M., Kostyuk, L. (2019). Development model of territorial communities business and public administration. Scientific Horizons, 9, 312

Tossutti, L. (2019). Engaging youths across the education divide: Is there a role for social capital? Canadian Journal of Political Science, 52(93), 501-520.

Verba, S., Pue, N. (2019). Partizipation in America: Political Democracy and Social Equality. New York: Harper and Row. 